\title{
Yoga for mental health: opportunities and challenges
}

\begin{abstract}
Background: Although widely popular for physical benefits, Yoga has been underutilized for the promotion of mental health. Health professionals and general public continue to remain in different about the suitability of Yoga for treating mental disorders, managing psychological wellness of patients and promoting mental health of the normal population.
\end{abstract}

Objective: Therefore, an attempt is made to document the key preventive, promotive and curative opportunities for mental health through yogic practices and identifying major hurdles in its practice. An evidence based review of related opportunities and challenges is presented.

Method: Thereview involved three steps i.e.framing review questions, search of multiple online databases, and interpretation of evidence-based opportunities.

Results and conclusion: There isenormous potential of yogic practices for improving mental health in families, schools, clinics and work settings. Major challenges involved in use of Yoga for protecting, managing and promoting mental health relate to paradigmatic choice, subtle process of yoga, methodological approach and practical constraints.

Keywords: breath-regulation, meditation, mental health, posture, yoga
Volume 2 Issue I - 2017

\author{
Arun Pratap Singh \\ Department of Psychology, MG International Hindi University, \\ India
}

Correspondence: Arun Pratap Singh, Department of Psychology, MG International Hindi University, India, Email jyotiarun I3@gmail.com

Received: August 08, 2016 | Published: January 25, 2017

\section{Introduction}

\section{Context of the study}

Yoga is currently blooming worldwide. It is being practiced by citizens of all the continents of the world. Indeed Yoga has become widely known and has been used for treatment of chronic health conditions, and management of the symptoms related to acute physical ailments. ${ }^{1}$ But, does it yield mental health benefits too? Can it replace traditional psychotherapy? Can it manage mental health conditions of patients suffering with serious physical ailments? Does Yoga constitute something more than maintaing body postures, breathing practices and meditation for promotion of psychological health? Can the great feats performed by the famous Yoga practitioners be empirically validated through scientific studies? These are some questions which have often been less attended. Although, governmental and non governmental organizations are gearing up for implementing Yoga in schools and other settings for improving health.however, the mental health service is still being perceived as dependent on deficiency-oriented models of treatment.

In the Indian tradition, Yoga was conceived as a pathway towards attainment of joy in life, freedom from sorrows, mental balance and peace. Since antiquity, the seekers of self-realization (often called as Rishis or Yogis) have been using yogic practices for restoring mindbody balance in order to make them capable for attaining spiritual realization. The ultimate states of human mental health development, have been described useing different terms. For example, Buddhists use notion of 'Nirvana', Samkhya 1 system uses 'Moksha', Vedantists use 'Atmasakshaatkar' etc. But all these notions converge in their meanings that it involves liberation from suffering. Sage Patanjali, who collated, coordinated and systematized the system of Yoga, declared the main objective of Yoga as regulation of mind in the first aphorism of famous Yoga Sutra (Yogah ChittvrittiNirodhah). ${ }^{2}$ Bhagvad Gita, which elaborates comprehensive typologies of Yoga, also states the need of Yoga for removing sorrow and increasing bliss in life. Hath Yoga, a yogic tradition focusing on physical modusoperandi for realizing deeper states of consciousness, emphasises on postures, breathing patterns, energy locks and contemplation to enhance energy and vitality.

Many features and practices of Yoga deal with psychological disorders and for promoting psychological wellness. First, Yoga can induce harmony in mind-body functioning. ${ }^{3}$ Second, being experientially-rooted; it can be adopted considerably with much ease in comparison to the existing psychological practices. ${ }^{4}$ Third, since training and taking the service of yoga therapist is cost effective it has promising potential to address mental health concerns of the people. According to an estimate in India alone, by using yoga for treatment of mental illnesses in India, approximately $\$ 145$ billion month may be saved which are spent to meet medication cost, doctor's fee, and travelling cost to meet the doctor. There are indirect savings also which acrue owing to loss of wages, disability, absenteeism and unimaginable substance abuse. ${ }^{5}$ Fourth, it can also alleviate multiple physical, emotional and social sufferings holistically. It may be noted that efficacy of any psychological therapy is multiply determined by factors either in the environment or in the attributes of the client or therapist but not by highly aclaimed theory-based techniques. Gradually demand for personalized, eclectic, and intuitive therapeutic approaches is on rise. Consequently, use of yogic practices as an adjunct to other forms of psychotherapy, is frequently reported. 
Yogic practices for mental health Since, ancient times, Yoga has been conceived as plural in its composition, meanings and practices (i.e., Hathayoga-PhysicalYoga, Gyan Yoga - Knowledge Yoga, Bhakti Yoga- Emotional Yoga, Raj Yoga-MentalYoga, LayayogaMeditationYoga) with singularity in its' objective to promote mindbody fitness. In contemporary times, Hathayoga (PhysicalYoga) is getting further diversified into different styles. Deeper understanding of these forms of yoga reveals that certain components including ethical and moral principles, posture (Asana), breathe regulation (Pranayama), chanting particular sounds (Mantra), introspection (Pratyahar), contemplation (Dharana) and meditation (Dhyan) are common among these.

\section{Ethical principles}

Ethical and moral principles are foundational constituents of Yoga. Two types of ethical and moral conditions-Yama (ethical standards including integrity, non-stealing, celibacy, treating others kindly and practicing moderation in use and storage of anything) and Niyama (individual observances for augmenting yoga practice) are espoused in Ashtanga Yoga tradition innunciated by Patanjali. In totality their practice not only strengthens the multiple effects of Yoga but also may provide additional psychological benefits.

\section{Asanas (postures)}

Yogic Asanas are bodily postures which stretch, strengthen, and relax different muscles and the various parts of body. They are performed in the state of relaxed awareness. Yoga Sutra defined Asana as a comfortable posture. These are known to be developed through careful observation of positions of different animals. Performance of an Asana rejuvenates the autonomic nervous system and lubricates muscles, ligaments and joints of the body through internal massaging and release of emotional blockages and centering of self in the present moment. ${ }^{6}$

In the Yogic tradition, next to Asana (posture) is regulation of breath (Pranayama). It is considered as a mainstay for the regulation of mental processes. In this technique, a variety of methods of inhalation of air, expelling it out and holding the air inside or outside the lungs are prescribed. In some highly advanced kinds of Pranayama (breathregulation) mere conscious visualization of receiving vital energy without any actual breathing is undertaken. Pranayama is well-known to reduce stress responses and improve physical and mental health.

Chanting of mantras has been an age-old tradition in the different religious. traditionsThe Hindu religious texts emphasize several benefits of chanting of 'Om' 'Gayatri mantra' and many other mantras. Empirical studies have suggested curative power of mantras for depression, stress responses ${ }^{8}$ and promoting cognitive functioning including improvement in attention-span, memory and self-concept. ${ }^{9}$

\section{Pratyahaar (contemplation)}

It involves withdrawal of sensory awareness from attentiveness for external objects. Different forms of Pratyahaar (i.e., Yoganidra, Shavasana, Vipashyana, Prekshaaetc) are widely known to alter the perceptions and mental responses to both external and internal stimuli, slowing -down of reactivity and instill a greater control over stressful situations. ${ }^{10}$ Yoga Nidra has been found to be effective in reducing symptoms of hypertension more than other types of relaxation techniques (i.e., Broota Relaxation Technique, Jacobson's Progressive Muscle Relaxation) used in psychotherapy. ${ }^{11}$
Meditation: In recent years growing body of evidence has grown on particular types of meditative techniques including focusing attention on present moment or a fixed stimulus such as one's breathe, some use imagery, or observe own thoughts rather than suppressing or engaging with them. Meditation has been found to yield positive effect on well-being among healthy as well as patients of severe disorders. In short-term, it reduces heart rate, respiration, skin conductance, cortisol levels, and increases alpha waves and promotes health, cognitive functioning, creativity, and empathy. It has also been useful for management of conditions such as hypertension, chronic pain, anxiety, and depression in long-term. ${ }^{12}$ In sync with potentials as mentioned above, the following section presents review of select yogic practices for their efficacy in handling health problems and challenges of well being.

\section{Method of review}

In order to identify mental health-linked opportunities offered by Yoga, first of all review questions were specified in clear, unambiguous and structured manner. Then appropriate databases (i.e. Medline, PubMed, The Cochrane Library, CEPS, EMBASE, PEDro) were searched through Google Scholar for following terms: "yoga and mental health" "Asana and mental health", "Pranayama and mental health", "mantra and mental health" "Pratyahar and mental health" "meditation and mental health" from January 1980 to August, 2014. The reference section of research papers was also reviewed. In a search for evidenced-based opportunities, we attended to all classified literature in part or full. It included peer reviewed journal articles, books and book chapters. In order to select only relevant articles and research papers, title was carefully read at first and if it appeared that it was appropriate then it was saved at a particular destination in a folder. Then each article was read and interpreted properly and evidence-based opportunities were noted carefully.

\section{Results and discussion}

In view of recently upheld view of mental health, ${ }^{13}$ we reviewed mental health opportunities of Yoga in dealing with minor mental health problems, resolving major disorders, population specific issues, healing to survivors of natural calamities, and for promotion of well-being. A summary of studiescovered in this work is presented in Table 1.

\section{Yoga and minor mental health problems}

Anxiety, stress and depression usually pervade in our lives. We often consider them as minor problems, but if they remain unresolved and unmanaged, they can lead to major psychological disorders. Evidence indicates that yoga is superior in its favorable effects for mitigating the effects of anxiety, stress and depression. ${ }^{1}$ In view of positive effect on feel-good neurotransmitters, alpha-wave activity, vagal tone, serum prolactin, but reducing oxidative stress, level of lipids, serum cortisol, down regulation of the hypothalamicpituitary-adrenal axis and alkalinity, Yoga may have immense utility for quietening arousal, tension, sadness, feelings of guilt, suicidal ideation and further the sense of harmony, balance, tranquility and deep relaxation at neurobiological level of functioning. ${ }^{14}$ Practice of postures can raise distress-tolerance level and reduce emotional eating tendencies in stressful situations. ${ }^{15}$ None of the entertainment activities including laughing, socializing, playing enjoyable game or shopping can calm our mental state to a greater extent than yoga because all these engagements need certain degree of stimulation of 
nervous system. Even walking has been reported not to induce greater effects on our emotional functioning and anxiety level than Yoga. ${ }^{16}$

In view of ample evidence for causal linkage between stress and many chronic diseases (i.e. heart disease, cancer, stroke, diabetes etc), Yoga can be appropriate as a stress management approach not only to reduce emotional negativity but also to reduce the burden of stressed produced diseases. ${ }^{17}$ Irritations which are part of daily life can be reduced through the practice of Yoga. In the patients suffering from life threatening illnesses also, it can reduce fatigue and insomnia. ${ }^{18}$

By developing mindfulness, Yoga reduces automatic reactive tendency and increases pro activity in difficult situations impelling anger or fear. ${ }^{19}$ If life style corrections get coupled with yoga practice, it may reduce anxiety and depression in persons suffering with gastrointestinal disorder ${ }^{20}$ and alienation and negative body image among normal adolescents [1]. Due to its positive effect in improvement of resilience and mind-body awareness, it can help people to adjust their behaviors according to environmental demand and personal feelings. Doing Yoga in group may increase cooperation and collectivism among the group members. ${ }^{2} 1$ By reducing stress responses including blood pressure, level of stress hormone cortisol, it can be used as potential alternative to pharmacological approach for patients with stress and anxiety.

\section{Dealing with somemajor disorders}

Traditionally, treatment of major psychological disorders in hospitals and clinics depended upona pharmacological approach. Although medicine-based cure provides instant relief but simultaneously it exposes the patients to several negative side-effects including inflammation and oxidative stress etc. ${ }^{22}$ Contrastingly, Yoga, without any potential side-effects, offers promising possibility for treating multiple psychological disorders. Several Yoga-based interventions have been developed for relief in symptoms of major depressive and anxiety disorders, ${ }^{23}$ autism spectrum disorders ${ }^{24}$ and eating disorders. ${ }^{25}$ Although there is little evidence, yet available research suggests that the practice of yoga can help managing selfobjectification, and disordered eating attitudes. ${ }^{26}$ It can help patients to reduce symptoms of Obsessive Compulsive Disorder. ${ }^{27}$

If used alone or adjunctively with medication, it can bring improvement in several symptoms of psychiatric disorders like schizophrenia (hallucination, delusion, motivation, affective flattering and ADHD) ${ }^{28}$ Yoga can be used for improving cognitive competencies including attention-span, memory and viso-motor speed among patients suffering with depression. In autistic children, practice of Yoga can improve sense of self, cognitive skills and social communicative behaviors.

\section{Relevance of yoga for de-addiction}

Yoga is increasingly being recognized for its ability to transform addicts' tendency from self-infliction to care of their bodies by reducing depression, and targeting their stress responses. ${ }^{29}$ The practice of Yoga helps people quitting smoking, alcohol and many other kinds of addiction. ${ }^{30}$ A recent study has indicated the efficacy of Yoga for gradually abstaining from the use of smoking. ${ }^{31}$

Yoga can assist dealing with several negative emotional states that generate, persist and compel to continue addiction. For example perceived stress, negative affect and physical symptoms of withdrawal increase individuals relapse for smoking can be easily mitigated through Yoga. Several addiction and substance abuse related psychological problems including stress, reduced capability for emotion regulation skills and thought suppression can be addressed by Yoga. ${ }^{32}$

\section{Resolving mental health problems in different segments of population}

Certain segments of world population have specific mental health related challenges. Because of the paucity of infrastructure and expertise, many health-related issues in different sections of populations in the developing countries cannot be effectively dealt by the existing system of pharmacology and psychotherapy.

Among maltreated segment of children, who exhibit impaired emotion regulation, Yoga may promote resilience. ${ }^{33} \mathrm{ADHD}$, which is highly prevalent among children, can be controlled effectively through different practices of Yoga. ${ }^{34}$ Lack of attentiveness and learning disabilities are often caused by neural imbalance. A combination of yogic postures and deep breathing practices cannot only handle these disorders but also channelize immense energy towards creative thinking and pro social activities. Yoga can be helpful for reducing the symptoms of eating disorders among teenagers. ${ }^{35}$ Students experiencing examination anxiety can benefit from Yoga. ${ }^{36}$ In normal adolescents, Yoga can increase the perceived fitness, self-esteem, clarity of life goals, adjustment, subjective well-being, empathy and academic competence. ${ }^{37,38}$

Elderly people often reportproblems of depression, insomnia, anxiety disorder, somatoform disorder, organic mental disorder and dementia. ${ }^{5}$ Yoga holds promise for resolving many of these problems. By handling depression, Yoga cannot only increase life satisfaction, quality of life, but also minimize social deprivation, loneliness, use of medication, cognitive decline and suicide also. Also, among some disadvantaged sections of society including urban slum dwellers, uprooted communities, urbanized tribal communities, who are characterized by high prevalence rate of mental disorders, Yoga can be used as an empowerment tool and adjunctive therapy.

\section{Yoga for the people affected by disasters}

Disasters destroy not only human lives and property but also threaten personal safety and collapse social support resulting into several disorders including post-traumatic stress disorder, major depressive disorder, generalized anxiety disorder, and panic disorder. ${ }^{39}$ By increasing present moment living, and mastery over body and mind to effectively interpret and tolerate physiological and psychological states, Yoga may help disaster affected individuals to tolerate physical and sensory experiences of fear and helplessness and increase affect tolerance and positivity of mood. ${ }^{40,41}$ Also, it can be used effectively to increase mental poise and ability to deal with several mental health related problems including difficulty in concentration, lack of interest or apathy, feelings of detachment, exaggerated startle response, sleep disturbances among military and paramilitary forces which often face terrorist attacks and war-like situation. ${ }^{42}$

\section{Promotion of mental health}

Promoting mental health is crucial to raise performance and enhancing the quality of life and health. By fostering psychological health, several social problems can be addressed effectively. Yoga, which has immense capacity to promote mental health, has not been used to cater to the needs of mental health promotion..$^{43}$ It can empower 
people to self-regulate their emotions, behaviors and cognitive processes ${ }^{44,45}$ Regular practice of Yoga may decreases the time taken to fall asleep, increase in the total number of sleep hours, and feeling of being fresh after sleep in the morning. Although the practice of Yoga only cannot be complete cure for many chronic ailments but it can uplift patient's mood and therefore play an important role in the management of wellness in patients suffering with different critical illnesses. ${ }^{10,46,47}$ Among cancer patients, for instance, it can increase acceptance of life in reality, energy, relaxation, quality of sleep and quality of life..$^{18}$

\section{Challenges for yoga research}

The tradition of Yoga consists of immense variety of behavioral, cognitive and emotional practices. ${ }^{48}$ It is like a vast sea which can subsume almost any practice blended with intention, awareness and relaxation. ${ }^{49}$ Now the question before us is how can we empirically evaluate the effects of Yoga? Should we use it as a whole system or stand-alone practice? Yoga emphasizes on the control and emancipation from multiple psychological difficulties through cultivation of awareness and insight about self by one self. ${ }^{50}$ Therefore aquestion arises as to what extent scientifically proclaimed neutral observation of the effects of yogic practices can actually provide glimpse of the benefits of doing Yoga for mental health. Yoga is based on the basic idea of holism and continuity of existence..$^{51}$ Therefore, to understand and investigate possible explanations; we need to undertake scrutiny of mainstream research tradition as following on relevance of Yoga for different types of mental health concerns. ${ }^{52}$

Any research endeavor needs to be explicit about what kind of paradigm it is going to adopt. Usually, mainstream research on Yoga and mental health is based on logical positivism..$^{53}$ But, in recent paradigmatic developments, ontological, epistemological, methodological and axiological assumptions of positivism are under scholarly debate. While, prestigious scientific methodology is based on dualistic notions of existence, Yogic paradigm cannot be put either under materialism or mentalism and dualism and monism. It takes into account materialist and mentalist accounts together. ${ }^{54}$ Now, the challenge for researcher is particularity of the paradigm which he/she has to adopt.

Another prominent challenge for modern Yoga research is: How can we use exact medical/psychological terms to refer to the subtle aspects and processes of existence? If we refer to vivid descriptions of self-realized Yogis, then recently upheld anatomical view (for example equating certain yogic terms such as 'chakras', 'upatyikas' with nervous plexus or ganglions) appears to marginalize actual meanings of yogic conceptualization of subtle structures, processes and states. ${ }^{55}$

The thired challenge for Yoga researcher is to arrive at consensus regarding meanings of terms used. For example Yoga may connote for a kind of life style, a set of practices or a particular state of conscious experience. There are many such terms which may have different meanings. Therefore, in view of existence of many schools of thought and traditions of Yoga providing different kinds of conceptual structures, ensuring unanimity in research terms seems to be arduous. ${ }^{56}$

Fourth challenge is whether Yoga researchers can think and work independently without being influenced by commonsensical portrayals of Yogic practices. Now, the question before Yoga researcher is also whether Yoga is being practiced in congruence with traditional Indian sense or being transformed to a transnational cultural set or being influenced by social change and modernization in interaction with local contexts and concerns. ${ }^{57}$

Many times it has been experienced that different yogic practices are relevant for treating same kind of maladies. These types of individual differences related to the effects of Yoga can be due to peculiarities of physical and mental constitution of the individual. According to Ayurveda, different persons may have differing pattern of the dominance of humors in their bodies which may mediate the effects of Yoga in complex manner. Therefore, evolving specific evidence-based prescriptions for different mental health concerns can be a tough job.

In the last two decades, many studies have been conducted to explore and evaluate the use of yogic practices for improving mental health. In popular academic parlance, RCTs are considered as 'gold standard' scientific approach to validate the effects of yoga. But, due to implausibility of double-blind trials, mental health associated effects are difficult to evaluate in true scientific sense. Also, modern yoga research is criticized for its reductionist stance and explaining the mechanisms of Yogic effects in terms of certain biochemical alterations and self-reports of subjective experiences. ${ }^{58}$

In any experimental study, a researcher faces an arduous task of separating the effect of yoga postures from other kinds of physical exercise. According to yogic philosophy, if any activity is performed with relaxed awareness and concentration only then it can be conceived as a yogic practice; otherwise it remains merely an exercise. In such a scenario, a researcher is likely to be perplexed with the task of invoking and measuring a particular type of attitude among the Yoga practitioners participating in a research.

According to yogic theory the effect of Yoga operates through qualitative alterations in deeper sheaths of consciousness. For instance, according to yogic tradition, mind is of four subtle layers. The ddeepest layer is 'chitta' (often defined as stream of consciousness), transformation of which results into experiences of divinity, mystical union, unbounded beauty, and space and time transcendence. Now, existing physical and psychological instruments cannot be capable of measuring subtle changes in these layers of mind. Also, while, effects of Yoga are conceptualized to operate through undetectable body's nadis or energy vortices residing at astral level of body, the same cannot be accessed through available instruments. Also, due to paradigmatic fixation to obhjectivist scientific enquiry, experiences at the levels of being are either rejected or believed to be ambiguous. ${ }^{59}$

Yoga identifies the notion of mental health and its causes rather differently. According to it, all kinds of suffering results from our identification with the body. Now, in yogic terms, this identification is a key mechanism to explain the difference in the effects of yogic practices for different individuals. But, challenge would be to articulate its asessment.

To gain the benefits of Yoga, a person needs to be motivated to practice. According to yogic theory, with enhancement of motivation, benefits of yoga are maximized. Now the problem is that if researchers get involved in motivating subjects then how will they be able to avoid intrusion of biases due to direct engagement of experimenter? And if not then how to overcome the effect of drop-out rate in any 
experimental research. Also, in view of individual variation in motivation level, researchers remain perplexed about the relevance of generalized statements for the outcomes of engagement in Yoga.

A researcher does not act in oblivion but in the midst of contextual influences. The act of interpreting particular form of Yoga is often given varied orientation by socio-political debates and controversies. In such a backdrop, a researcher often gets baffled with the task of what to research on and what not to research. The researcher may be preoccupied by certain type of perception due to his/her training in particular type of research and disciplinary tradition; which may further prevent from unearthing the culturally sensitive mechanisms underlying the practice of Yoga.

\section{Conclusion}

This review suggests huge potential of Yoga for mental health. Yoga can empower individuals' positively to take charge of their own psychological wellness and save a large expenditure for treatment and prevention of mental health problems. Yoga can take the form of a new therapy for curative, preventive, protective and promotive objectives at schools, hospitals, health care centers and in family. It can offer immense help in sustaining wellness, addressing concerns related with increasing suicidal tendencies due to examination anxiety, deal with frustration and conflicts in society and to opt career choices with full awareness of one's own abilities and potentials.

Psychology researchers need to play an important role to increase awareness of different forms of Yoga and associated benefits and bust negative stereotypes related to Yoga. We need to unearth the psychological relevance of different ethical and moral guidelines espoused in different yogic traditions. Also, researchers need to work on environmental and individual constraints in the practice of Yoga. To this end researcher has to experience Yoga not only from a third or second person's view but also as a first person. For this, there is a need for greater collaboration between practitioners and researchers. Eclectic use of quantitative and qualitative approaches of research can help to demystify Yoga and make it possible to be accepted as one of the suitable personalized form of therapy and approach for psychological welfare of human being.

\section{Acknowledgements}

None.

\section{Conflict of interest}

The author declares no conflict o interest.

\section{References}

1. Woodyard C. Exploring the therapeutic effects of yoga and its ability to increase quality of life. International Journal of Yoga. 2011;4(2):49-54.

2. Iyengar BKS. The illustrated light on yoga. USA: Harper Collins; 2005.

3. Singh AP, Misra G. Adolescent life style: Prevalence of risk and promotive factors of health. Psychology \& Developing Societies. 2012;24(2):145160 .

4. Kakar S. Psychoanalysis and eastern spiritual traditions. J Anal Psychol. 2003;48(5):659-678.

5. Math SB, Srinavasaraju R. Indian psychiatric epidemiological studies: Learning from the past. Indian Journal of Psychiatry. 2010;52(S1):S95-103.

6. Brisbon NM, Lowery GA (2011) Mindfulness and levels of stress: A comparison of beginner and advanced Hatha yoga practitioners. J Relig Health 50(4): 931-941.

7. Sengupta P. Health impacts of yoga and pranayama: a state-of-the-art review. Int J Prev Med. 2011;3(7):444-458.

8. Telles S, Nagarathna R, Nagendra HR. Autonomic changes while mentally repeating two syllables-one meaningful and the other neutral. Indian $J$ Physiol Pharmacol. 1998;42(1):47-63.

9. Ghaligi S, Nagendra HR, Bhatt R. Effect of Vedic chanting on memory and sustained attention. Indian Journal of Traditional Knowledge. 2006;5(2):177-180.

10. Banerjee B, Vadiraj HS, Ram A, et al. Effects of an integrated yoga program in modulating psychological stress and radiation-induced genotoxic stress in breast cancer patients undergoing radiotherapy. Integr Cancer Ther. 2007;6(3):242-250.

11. Broota A, Verma R, Singh A. Role of relaxation in hypertension. Journal of Indian Academy of Applied Psychology. 1995;21:29-36.

12. Waters L, Barsky A, Ridd A, et al. Contemplative education: a systematic evidence-based review of the effect of meditation intervention in schools. Educational Psychology Review. 2015;27(1):103-104.

13. Lamers SMA, Pelin G, Beata EK, et al. Conceptualizations of Mental Health across Europe: Comparing Psychology with Science and Engineering Students. Journal of European Psychology Students. 2014;5(2):3-7.

14. Madanmohan, Bhavanani AB, Sanjay Z, et al. Effects of eight week yoga therapy program on cardiovascular health in hypertensives. Indian Journal of Traditional Knowledge. 2013;12(3):535-541.

15. Medina J, Hopkins L, Powers M, et al. The effects of a hatha yoga intervention on facets of distress tolerance. Cogn Behav Ther. 2015;44(4):288-300

16. Streeter CC, Whitefield TH, Owen L, et al. Effect of Yoga versus walking on mood, anxiety, and brain GABA levels: A randomized controlled MRS study. J Altern Complement Med. 2010;16(11):1145-1152.

17. Sharma VK, Das S, Mandal S, et al. Effect of Sahaj Yoga on depressive disorders. Indian J Physiol Pharmacol. 2005;49(4):462-468.

18. Carson JW, Carson KM, Porter LS, et al. Yoga for women with metastatic breast cancer: Results from a pilot study. J Pain Symptom Manage. 2007;33:331-341.

19. Witkiewitz K, Lustyk MK, Bowen S. Retraining the Addicted Brain: A Review of Hypothesized Neurobiological Mechanisms of MindfulnessBased Relapse Prevention. Psychol Addict Behav. 2012;27(2):351-365.

20. Mishra M, Sinha RK. Effects of yogic practices on depression and anxiety. SIS Journal of Projective Psychology and Mental health. 2001;8:23-27.

21. Wiltermuth SS, Heath CC. Synchrony and cooperation. Psychological Science. 2009;20(1):1-5.

22. Trivedi MH, Rush AJ, Wisniewski SR, et al. Evaluation of outcomes with citalopram for depression using measurement-based care in STAR*D: implications for clinical practice. Am J Psychiatry. 2006;163(1):328-340.

23. Shapiro D, Cook IA, Davydov DM, et al. Yoga as a Complementary treatment of depression: effects of traits and moods on treatment outcome. Evid Based Complement Alternat Med. 2007;4(4):493-502.

24. Radhakrishna S, Nagarathna R, Nagendra HR. Integrated approach to yoga therapy and autism spectrum disorders. J Ayurveda Integr Med. 2010;1(2):120-124.

25. Rawat R, Pandya C. Effect of yogic intervention on eating disorder cognitions among adolescent girls in India. International Journal of Applied Research. 2016;2(4):668-673. 
26. Dittmann KA, Freedman MR. Body awareness, eating attitudes, and spiritual beliefs in women practicing yoga. Eat Disord. 2009;17(4):273292.

27. Datta J, Broota A. Managing obsessive compulsive disorder (OCD) with yoga and cognitive behavioural therapy. Journal of Research and Applications in Clinical Psychology. 2000;3:41-50.

28. Behere RV, Arasappa R, Jagannathan A, et al. Effect of yoga therapy on facial emotion recognition deficits, symptoms and functioning in patients with schizophrenia. ActaPsychiatrica Scandinavia. 2011;123(2):147-153.

29. Vedamurthachar A, Janakiramaiah N, Hegde JM, et al. Anti-depressant efficacy and hormonal effects of sudarshanakriyayoga (SKY) in alcohol dependent individuals. Journal of Affective Disorder. 2006;94(1-3):249253.

30. Kissen M, Kissen Kohn DA. Reducing addictions via the self-soothing effects of yoga. Bull Menninger Clinic. 2009;73(1):34-43.

31. Bock BC, Fava JL, Gaskins R, et al. Yoga as a complementary treatment fo smoking cessation in women. Journal of Women Health. 2012;21(2):240 248.

32. Garland EL, Boettiger CA, Howard MO. Targeting cognitive-affective risk mechanisms in stress-precipitated alcohol dependence: an integrated biopsychosocial model of automaticity, allostatic, and addiction. Medical Hypotheses. 2011;76(5):745-754.

33. Waechter RL, Wekerle C. Promoting resilience among maltreated youth using meditation, yoga, tai chi and qigong: a scoping review of the literature. Child Adolescent Social Work Journal. 2015;32(1):17-31.

34. Haffner J, Roos J, Goldstein N, et al. The effective- ness of body-oriented methods of therapy in the treatment of attention-deficit hyperactivity disorder (ADHD): results of a controlled pilot study]. Zeitschrift fur Kinder- und Jugendpsychiatrie und Psychotherapie. 2006;34(1):37-47.

35. McIver S, O Halloran P, McGart land M. Yoga as a treatment for binge eating disorder: a preliminary study. Complementary Therapy Medicine. 2009;17(4):196-202.

36. Pant G, Bera TK, Uddhav SS. Yoga for controlling examination anxiety, depression and academic stress among students appearing for Indian board examination. International Journal of Recent Scientific Research. 2013. p. $41-44$.

37. Malathi DA, Shah N, Patil NS. Effects of Yogic practices on subjective wellbeing. Indian Journal of Physiological Pharmacology. 2000;44(2):202206.

38. Khalsa SB, Schultz LH, Cohen D, et al. Evaluation of the mental health benefits of Yoga in a secondary school: A preliminary randomized controlled trial. The Journal of Behavioural Health Services \& Research. 2012;39(1):80-90.

39. Math SB, Girimaji SC, Benegal V, et al. Psychosocial aspects of Andaman and Nicobar islands: Assessments and intervention in the early phase. International Review of Psychiatry. 2006;18(3):233-239.

40. Jindani F, Nigel T, Khalsa SB. A Yoga intervention for post-traumatic stress: A preliminary randomized control trial. Evidence-based Complementary and Alternative Medicine. 2015: ID 351746:8.

41. Kolk BA, Stone L, West J, et al. Yoga as an adjunctive treatment for posttraumatic stress disorder: a randomized controlled trial. Journal of Clinical Psychiatry. 2014;75:1-5.

42. Stankovic L. Transforming Trauma: A qualitative feasibility study of integrative restoration (iRest) Yoga Nidra on combat-related PostTraumatic stress disorder. International Journal of Yoga Therapy. 2011;21(1):23-37.
43. Tripathi RC, Bano S. Psychological well-being through yogic exercise. Journal of Physical Education Research. 2015;2(11):62-67.

44. Noggle JJ, Steiner NJ, Minami T, et al. Benefits of yoga for psycho-social well-being in a US High school curriculum: A preliminary randomized controlled trial. J Dev Behav Pediatr. 2012;33(3):193-201.

45. Yoshikara K, Hiramoto T, Oka T, et al. Effects of 12 weeks of yoga training on the somatization, psychological symptoms, and stress-related biomarkers of healthy women. Biopsychosoc Med. 2014;8(1):1-9.

46. Raghavendra MR, Nagendra HR, Raghuram N, et al. Influence of yoga on mood states, distress, quality of life and immune outcomes in early stage breast cancer patients undergoing surgery. Int J Yoga. 2008;1(1):11-20.

47. Vadiraja HS, Raghavendra RM, Nagarathna R, et al. Effects of a yoga program on cortisol rhythm and mood states in early breast cancer patients undergoing adjuvant radiotherapy: a randomized controlled trial. Integral Cancer Therapy. 2009;8(1):37-46.

48. Anita, Gaur DR, Vohra AK, Subash S, et al. Prevalence of psychiatric morbidity among 6 to 14 year old children. Indian Journal of Community Medicine. 2007;28(3):133-137.

49. Bower JE, Garet D, Sternlieb B, et al. Yoga for persistent fatigue in breast cancer survivors: a randomized controlled trial. Cancer. 2011;118(15):3766-3775.

50. Chen KM, Chen MH, Chao HC, et al. Sleep quality, depression state, and health status of older adults after silver yoga exercises: Cluster randomized trial. Int J Nurs Stud. 2009;46(2):154-163.

51. Halpern J, Cohen M, Kennedy G, et al. Yoga for improving sleep quality and quality of life for older adults. Altern Ther Health Med. 2014;20(3):37-46.

52. Jadhav SG, Havalappanavar NB. Effect of yoga intervention on anxiety and subjective wellbeing. Journal of Indian Academy of Applied Psychology. 2009;35(11):27-31.

53. Kadachha D, Soni N, Parekh A. Effects of yogasana on balance in geriatric population. International Journal Physiotherapy and Research. 2016;4(2):1401-1407.

54. Kovačič T, Kovačič M. Impact of relaxation training according to Yoga In Daily Life ${ }^{\circledR}$ system on self-esteem after breast cancer surgery. J Altern Complement Med. 2011;17(2):1157-1164.

55. Larson GM. Eliminative materialism, eliminative dualism and the philosophy of Yoga. In: Girishwar Misra, editor. Psychology and Psychoanalysis. Philosophy and culture in Indian civilization, India: 2013. p. 19-40.

56. Manjunath NK, Telles S. Influence of Yoga and Ayurveda on self-rated sleep in a geriatric population. Indian J Med Res. 2005;121(5):683-690.

57. Moadel AB, Shah C, Wylie Rosett J, et al. Randomized controlled trial of yoga among a multiethnic sample of breast cancer patients: effects on quality of life. J Clin Oncol. 2007;25(28):4387-4395.

58. Telles S, Naveen KV, Dash M, et al. Effect of yoga on self-rated visual dismfort in computer users. Head \& Face Medicine. 2006;2(46):1-6.

59. Vadiraja HS, Rao MR, Nagarathna R, et al. Effects of yoga program on quality of life and affect in early breast cancer patients undergoing adjuvant radiotherapy: a randomized controlled trial. Complement Ther Med. 2009;17(5-6):274-280. 